\title{
STRESS ANALYSIS AND FATIGUE TEST ON PARTIALLY OVERLAPPED CHS K-JOINTS
}

\author{
T. Sopha, T.B.N. Nguyen, S.P. Chiew ${ }^{1, *}$, C.K. Lee and S.T. Lie \\ ${ }^{1}$ School of Civil and Environmental Engineering, Nanyang Technology University \\ 50 Nanyang Avenue, Singapore 639798, Tel: (65) 6790 5294; Fax: (65) 67921650 \\ *(Corresponding author: E-mail: cspchiew@ntu.edu.sg)
}

\begin{abstract}
This paper presents the experimental studies of two partially overlapped CHS K-joints specimens (Specimens S1 and S2) with through brace subjected to basic and combined loads. The stress analysis of the joints revealed the maximum stress concentration factor (SCF) to be located on the brace side. Then, the maximum SCF was compared with existing Efthymiou's formulae. It is observed that the Efthymiou's formulae are over-conservative in in-plane bending load case (IPB), but in axial load case (AX) are not conservative. In addition, the fatigue life was also compared with existing S-N curves. The S-N curve was found to be marginally conservative for first specimen, but it was not conservative for other one.
\end{abstract}

Keywords: Partially overlapped K-joints, stress concentration and stress intensity factor, fatigue failure, surface and through-thickness cracks

\section{INTRODUCTION}

Due to the ease of fabrication and the existence of many direct calculation methods to assess the joint capacity, simple tubular T-, Y- and non-overlap K-joints are widely used connection types for the construction of offshore steel jackets. When compared with a K-joints with gap, a partially overlap K-joints may has a higher fabrication costs due to the complex end profile of the overlap brace. However, partially overlap K-joint has a higher residual capacity as a result of their optimized load transfer pattern. In fact, recently, in a case study comparing the costs of three K-joints design options [1], it was found that after having considered the material and fabrication costs, an overlap joint is the cheapest option, with the fabrication cost actually being significantly cheaper than that of the alternative canned gap joint. However, in the past, very few research works were carried out to study the fatigue behaviour of partially overlap circular hollow section (CHS) $\mathrm{K}$-joints and virtually no information regarding the fatigue strength of overlapped CHS K-joints is available. The main objective of this study is to investigate the stress concentration factor (SCF) and check measured SCF-values with existing formulae, investigate the stress intensity factor (SIF) distributions for a partially overlapped CHS K-joint under different cyclic loading conditions, and evaluate the applicability of present S-N curve in design of partially overlapped CHS K-joints.

\section{TEST RIG AND LOADING SYSTEM}

The "orange" test rig shown in Figure 1 was used to test a partially overlap CHS K-joint subjected to axial (AX), in-plane bending (IPB), out-of-plane bending (OPB) and the combination of these three basic load cases. The rig is capable of applying static loading to determine the hot spot stress (HSS) distributions, as well as cyclic loading to determine the fatigue life. Two $250 \mathrm{kN}$ and one $150 \mathrm{kN}$ capacity servo-hydraulic actuators were installed to apply the three basic load cases. The loads were applied along the three mutually perpendicular axes. 


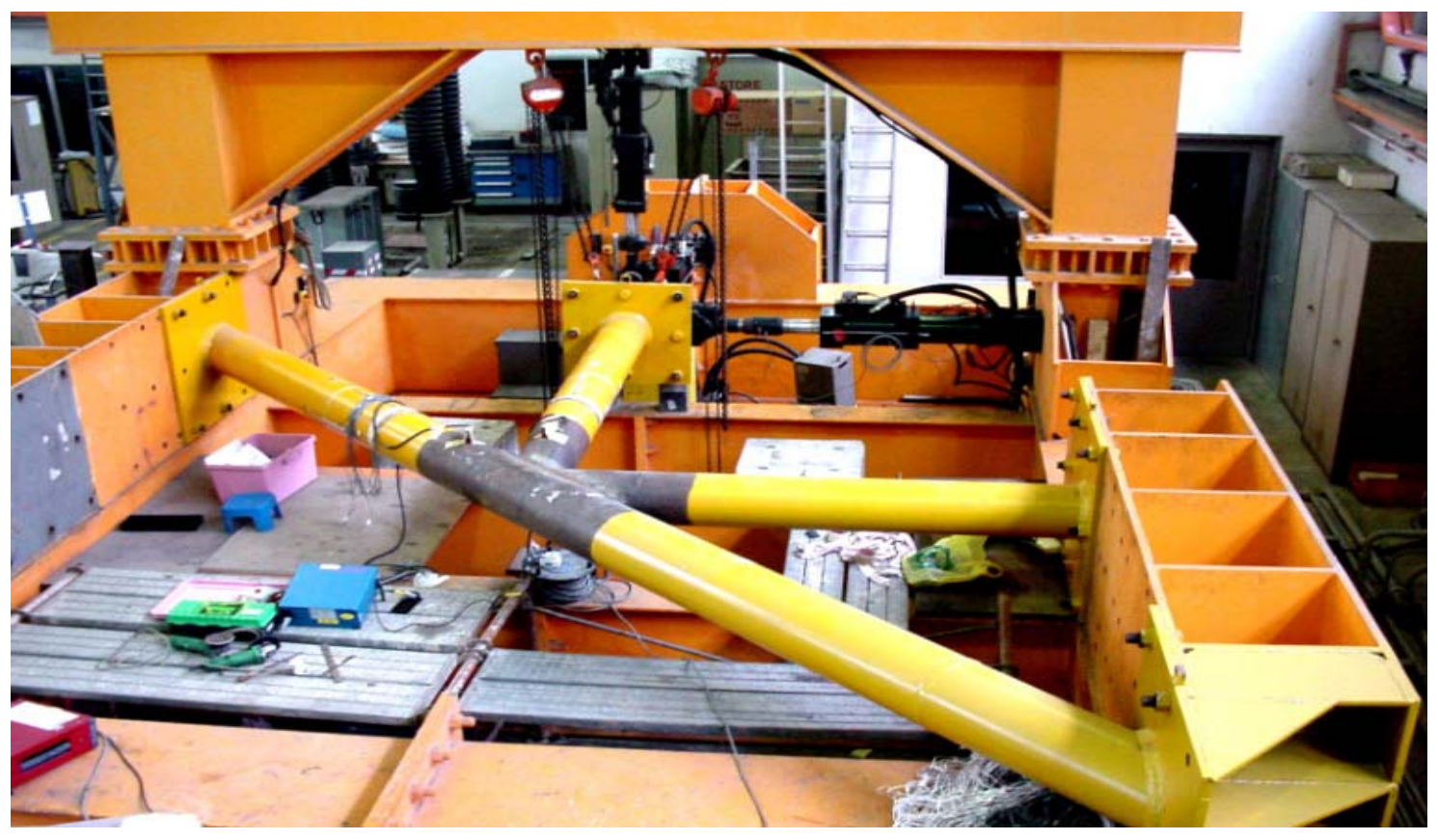

a) Overview of Test Rig

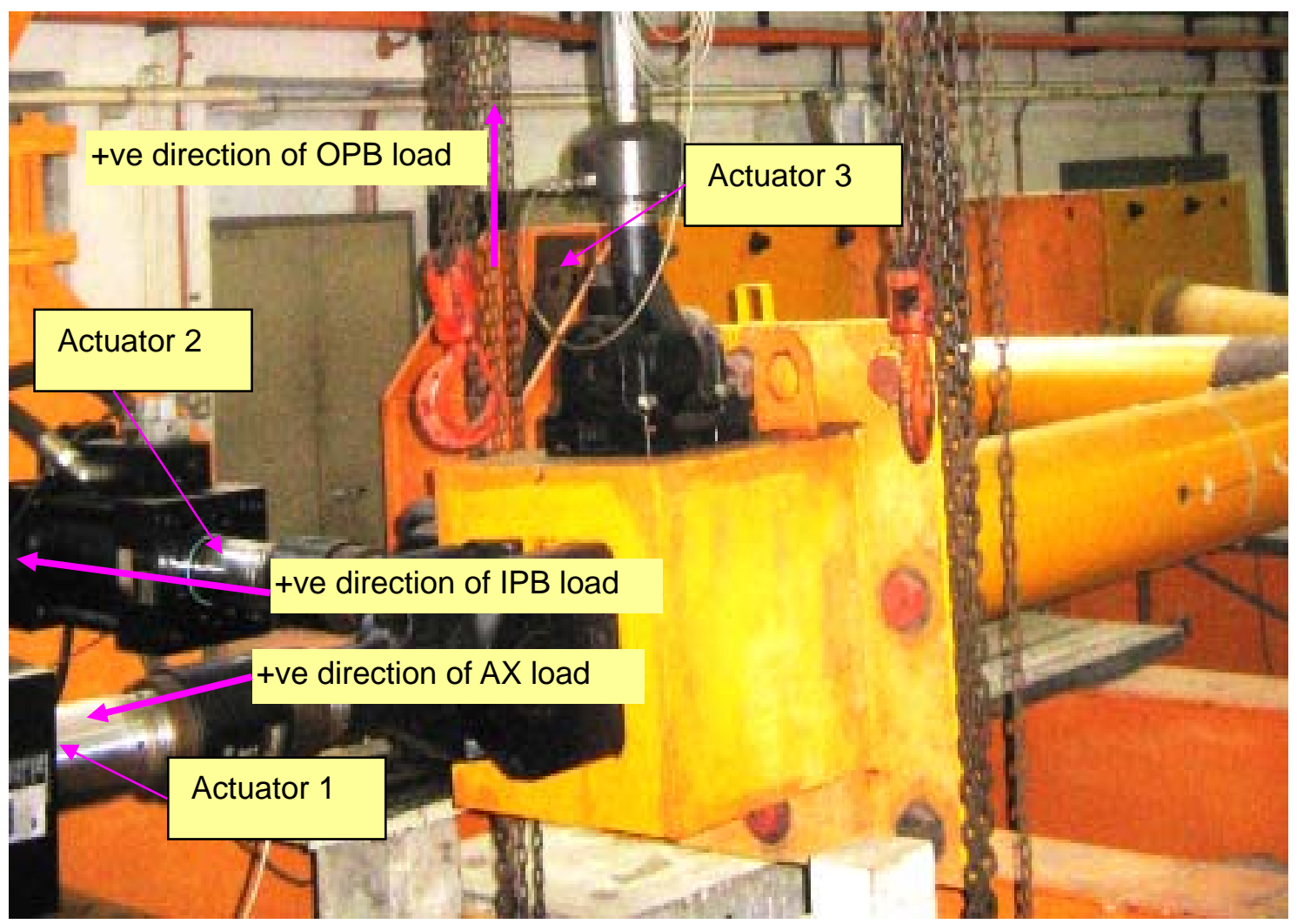

b) Three Actuators 1, 2 and 3

Figure 1. The “Orange” Test Rig 


\section{TEST SPECIMEN}

The two partially overlapped K-joint specimens (S1 and S2) were fabricated from circular hollow sections. The dimensions and geometric ratios of the joints are given in Figure 2 and Table 1. The material properties of these CHS are shown in Table 2. The intersecting profile of the braces was constructed according to the AWS specifications and ultrasonic checked was conducted to ensure the quality of the welding. Both specimens were installed by fixing the two ends of the chord and the overlapping brace. The external loads were applied at the end of the through brace.

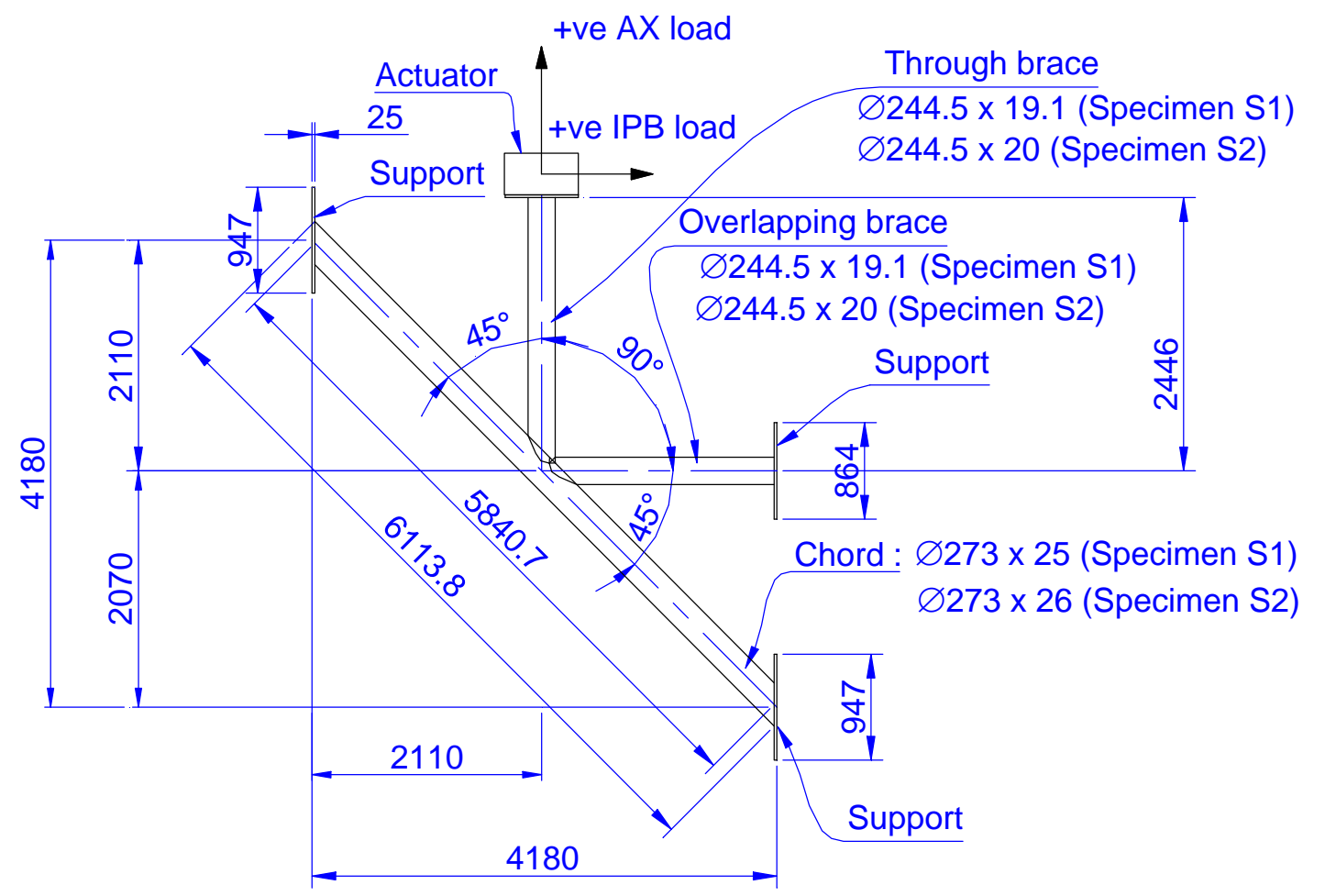

Figure 2. Configuration of Test Specimens

Table 1(a). Geometric Parameters of Specimens

\begin{tabular}{|c|c|c|c|c|c|}
\hline Specimens & $\begin{array}{c}\text { Chord } \\
\text { diameter } \\
(\mathrm{mm}), \mathrm{D}\end{array}$ & $\begin{array}{c}\text { Chord } \\
\text { thickness } \\
(\mathrm{mm}), \mathrm{T}\end{array}$ & $\begin{array}{c}\text { Brace } \\
\text { diameter } \\
(\mathrm{mm}), \mathrm{d}\end{array}$ & $\begin{array}{c}\text { Brace } \\
\text { thickness } \\
(\mathrm{mm}), \mathrm{t}\end{array}$ & $\begin{array}{c}\text { Eccentricity } \\
(\mathrm{mm}), \mathrm{e}\end{array}$ \\
\hline S1 & 273 & 25 & 244.5 & 19.1 & 0 \\
\hline S2 & 273 & 26 & 244.5 & 20.0 & 0 \\
\hline
\end{tabular}

Table 1(b). Non-dimension Parameters

\begin{tabular}{|c|c|c|c|c|}
\hline Specimens & $\beta=\frac{d}{D}$ & $2 \gamma=\frac{D}{T}$ & $\tau=\frac{t}{T}$ & $\begin{array}{c}\mathrm{O}_{\mathrm{v}} \\
(\%)\end{array}$ \\
\hline S1 & 0.895 & 10.92 & 0.764 & 21 \\
\hline S2 & 0.895 & 10.50 & 0.769 & 21 \\
\hline
\end{tabular}

Table 2. Material Properties of the Specimens

\begin{tabular}{|c|c|c|c|}
\hline \multirow{2}{*}{ Specimens } & Member & $\begin{array}{c}\text { Yield strength } \\
(\mathrm{MPa})\end{array}$ & $\begin{array}{c}\text { Modulus of } \\
\text { Elasticity (GPa) }\end{array}$ \\
\hline \multirow{2}{*}{ S1 } & Chord & 252.66 & 205.33 \\
\cline { 2 - 4 } & Brace & 404.54 & 204.42 \\
\hline \multirow{2}{*}{ S2 } & Chord & 403.9 & 207.5 \\
\cline { 2 - 4 } & Brace & 426.9 & 201.9 \\
\hline
\end{tabular}




\section{STRAIN GAUGE LOCATION}

Strain gauges were placed near the weld toe as shown in Figure 3. At each spot, pairs of strain gauges were used to measure the distribution of the strain components perpendicular and parallel to the weld toe. In addition, in order to detect any secondary bending moment caused by load eccentricity and joint flexibility [2,3,4], a pair of strain gauges were also installed at the two cross-sections along the through brace with a distance equal three times of the diameter of the brace.

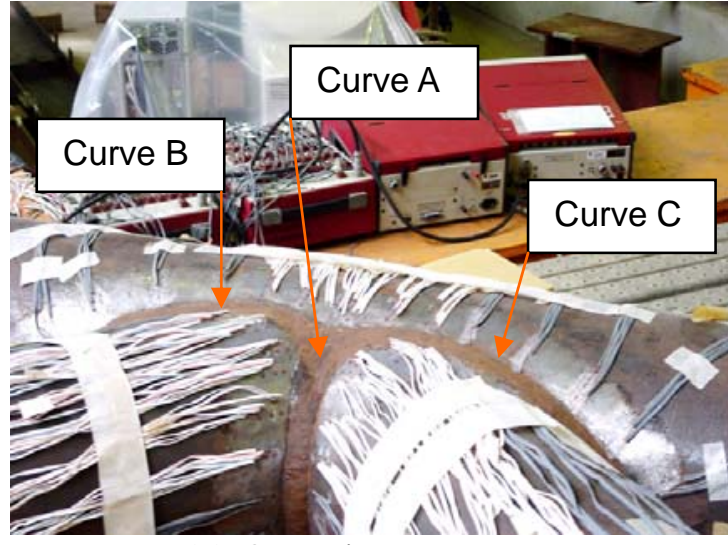

(a) Overview

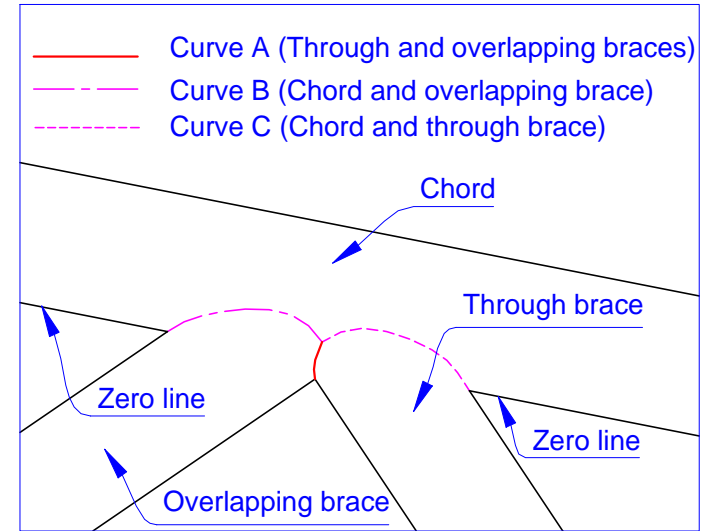

(b) Scheme of Curves

Figure 3: Strain Gauge Location

\section{STATIC TEST PROCEDURE}

A series of load cases consisting of AX, IPB, OPB loadings and combinations of them were chosen and tested. Each specimen was first subjected to an incremental static load on one axis, and the strains were checked against linearity and zero drift to indicate shakedown of residual stress [5]. Before starting the actual static tests, the applied loads on each actuator were preprogrammed. The actuators were then ramped to the predetermined loads. The strain gauge readings were eventually recorded by special software for further calculations.

\section{STATIC TEST RESULTS}

After strain gauges values were recorded, the hot spot strain perpendicular and parallel to the weld toe, $\left(\xi_{\perp}\right)$ and $\left(\xi_{/ /}\right)$, were obtained by the quadratic extrapolation method. The strain concentration factor (SNCF) was calculated as

$\mathrm{SNCF}=\xi_{\perp} / \xi_{\mathrm{n}}$

where $\xi_{\mathrm{n}}$ is the nominal strain obtained from the readings of the four strain gauges attached along the through brace member. The stress concentration factor (SCF) was calculated as

$\operatorname{SCF}=\operatorname{SNCF}\left(1+v \xi_{/ / /} \xi_{\perp}\right) /\left(1-v^{2}\right)$

where $v$ is the Poisson's ratio of the material.

The average value of experimental SCF distributions along the weld toe from two specimens had been obtained from the static tests under different basic load cases are shown in Table 3. The SCFs 
at the heel, crown and saddle positions of the chord and braces obtained by using Efthymiou's Formulae [6] are also listed in Table 3. From Table 3, it is observed that in all the load cases, SCFs at the through brace are greater than that at the chord. Meanwhile, for IPB load case, SCFs predicted by Efthymiou's formulae [6] show over-conservative by $47 \%$ and $15 \%$ for chord and brace respectively. However, for AX load case, the formula SCF values are not conservative by $40 \%$ and $26 \%$ for chord and brace respectively.

Table 3. Experimental SCF Values in HSS Location and Results Predicted By Efthymiou's Formulae [2]

\begin{tabular}{|c|l|c|c|c|c|}
\hline \multirow{2}{*}{ Load cases } & \multirow{2}{*}{ Method } & \multicolumn{2}{|c|}{ Through brace side } & \multicolumn{2}{c|}{ Overlapping brace side } \\
\cline { 3 - 6 } & $\mathrm{SCF}_{\text {chord }}$ & $\mathrm{SCF}_{\text {brace }}$ & $\mathrm{SCF}_{\text {chord }}$ & SCF \\
& Test & 2.67 & $\mathbf{2 . 8 8}$ & 2.02 & 1.37 \\
\cline { 2 - 6 } & $\begin{array}{l}\text { Efthymiou's } \\
\text { formulae }\end{array}$ & 1.6 & 2.11 & - & - \\
\hline \multirow{3}{*}{ IPB } & Test & 0.82 & 2.31 & - & 0.77 \\
\cline { 2 - 6 } & $\begin{array}{l}\text { Efthymiou's } \\
\text { formulae }\end{array}$ & 1.57 & $\mathbf{2 . 7 0}$ & - & - \\
\hline \multirow{2}{*}{ OPB } & Test & 0.86 & 1.22 & - & - \\
\cline { 2 - 6 } & $\begin{array}{l}\text { Efthymiou's } \\
\text { formulae }\end{array}$ & - & - & - & - \\
\hline
\end{tabular}

The stress distributions measured in the static test under combined AX and IPB loadings and the corresponding values computed by using the superposition method for both specimens are shown in Figure 4. From Figure 4, it can be seen that for Specimen S1, under the actions of AX and positive IPB loading, the peak HSS appeared at the heel of the through brace for curve $C$ with a value of 382.32 MPa. For Specimen S2, under the action of AX and negative IPB, the peak HSS appeared at the crown of the through brace for curve A with a value of $285.92 \mathrm{MPa}$. Furthermore, the results computed by the superposition methods agree well with the experimental results.

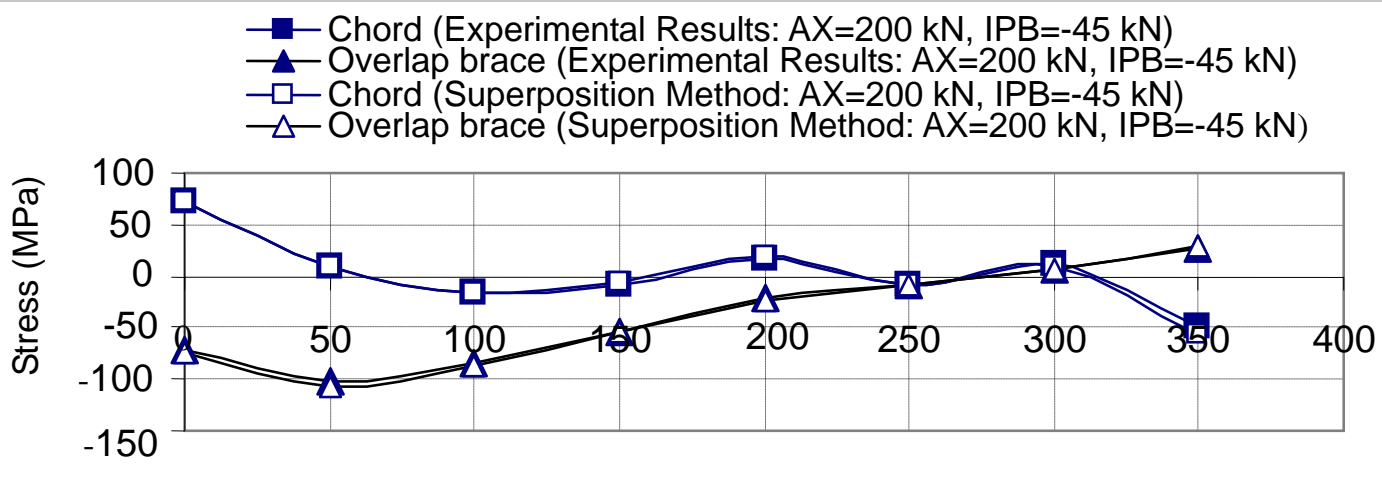

Distance from 0 line $(\mathrm{mm})$

a) Curve C 


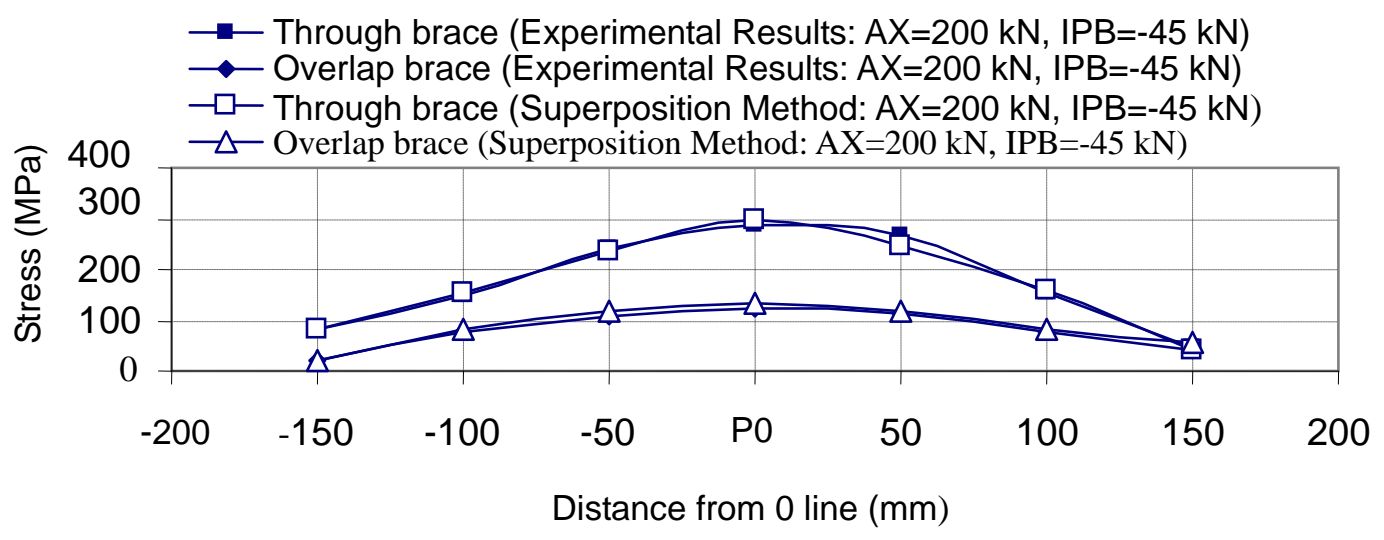

b) Curve $\mathrm{A}$

Figure 4. HSS Distributions

\section{FATIGUE TEST INVESTIGATION}

The alternating current potential drop (ACPD) technique [7-11] was used to monitor the growth of surface crack at expected crack growth location. Based on the peak HSS locations detected during the static test, 32 ACPD probes were placed at equal intervals of $10 \mathrm{~mm}$ along the weld toe of the through brace around curve C for Specimen S1 and around curve A for Specimen S2 (Figure 5). Both specimens were tested in air under sinusoidal constant amplitude loading with load frequency of $0.2 \mathrm{~Hz}$ through out the test. The cyclic loading patterns applied are shown in Figure 6.During the fatigue test, crack profiles were recorded using a scan interval equivalent to 180 cycles of the cyclic loading applied. For both specimens, the cyclic loading was applied until the crack had well penetrated the through brace thickness.

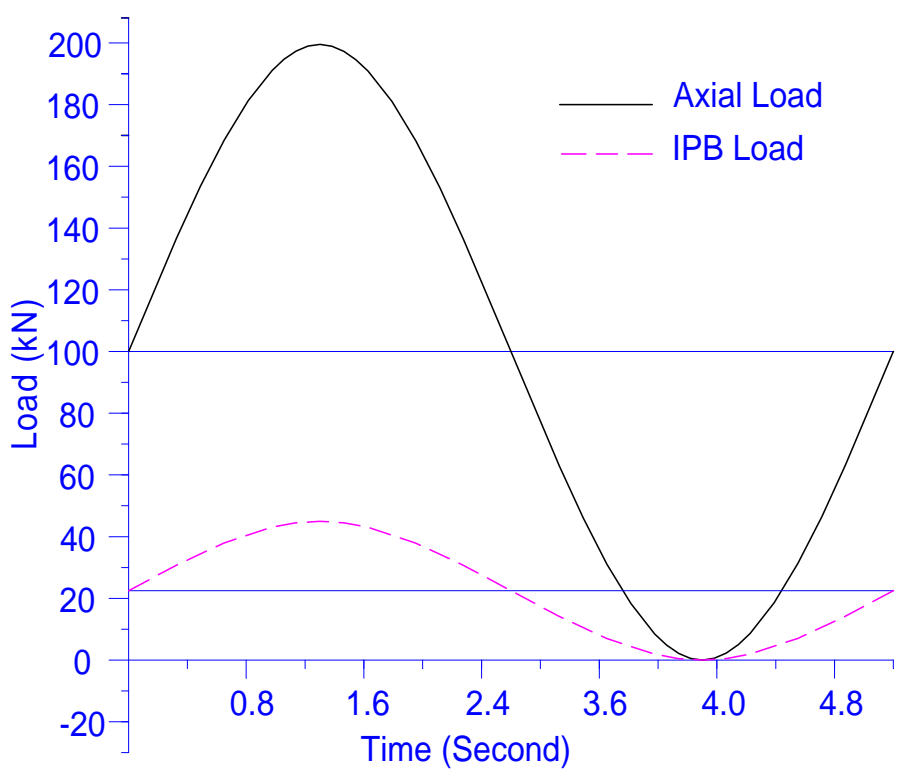

(a) Cyclic Load Applied to Specimen S1 


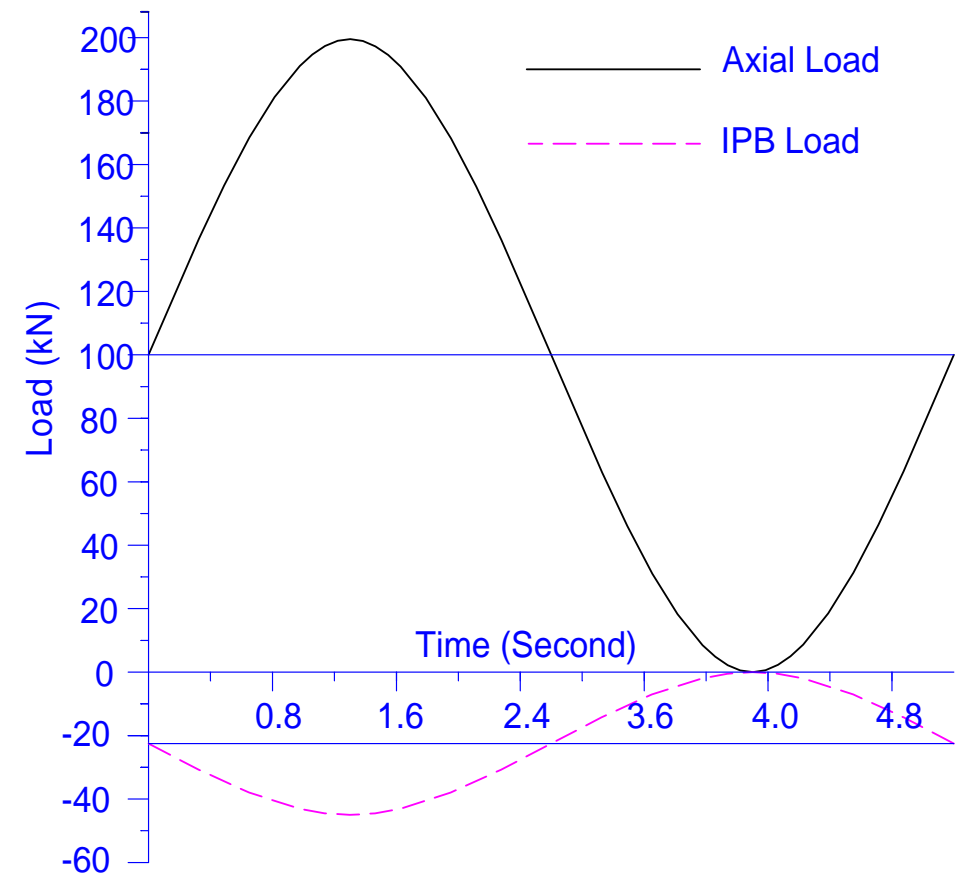

(b) Cyclic Load Applied to Specimen S2

Figure 5. Cyclic Load Applied to Specimens

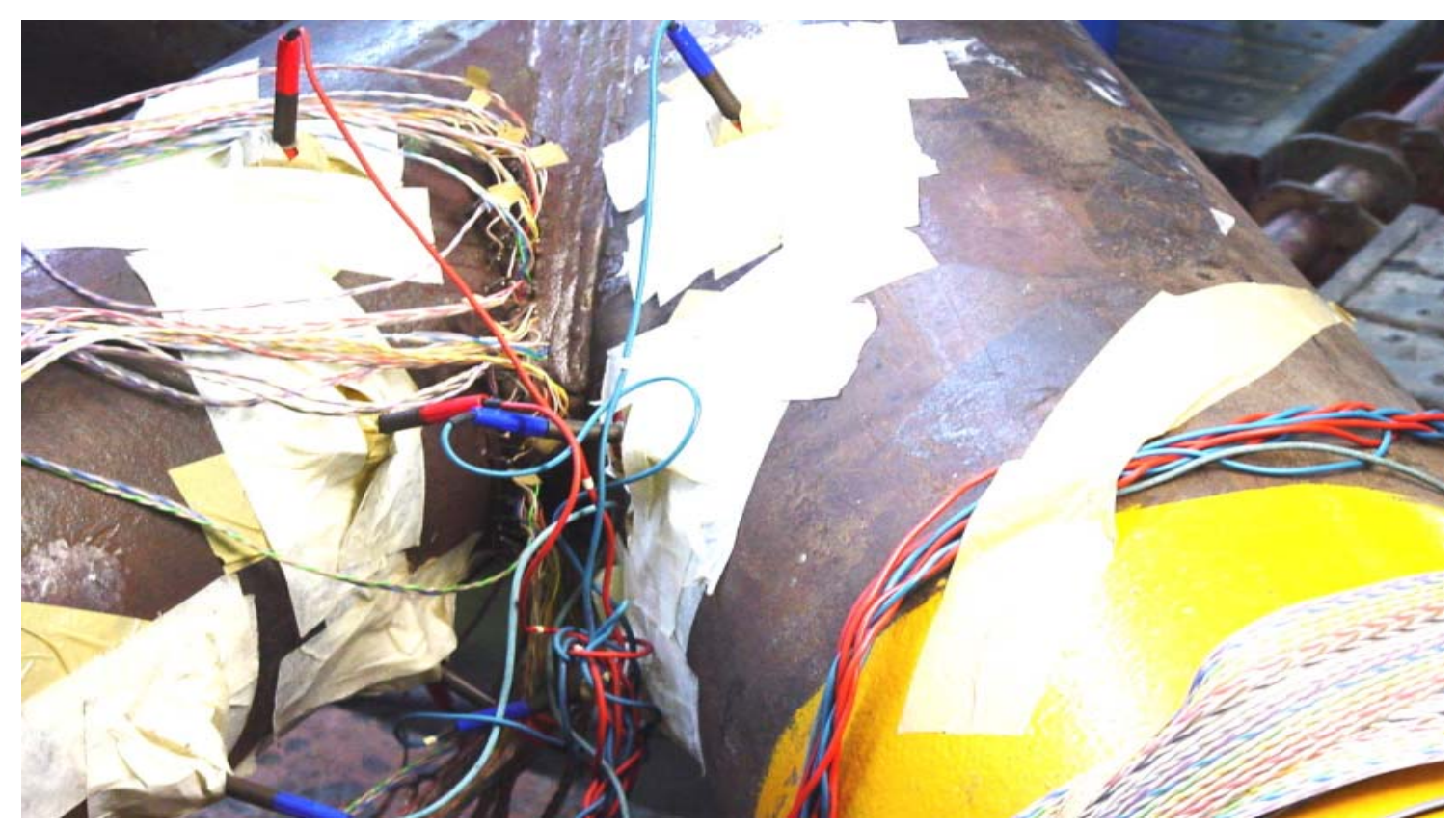

(a) Close-up View of Probes and the Connecting Cables of Specimen S1 


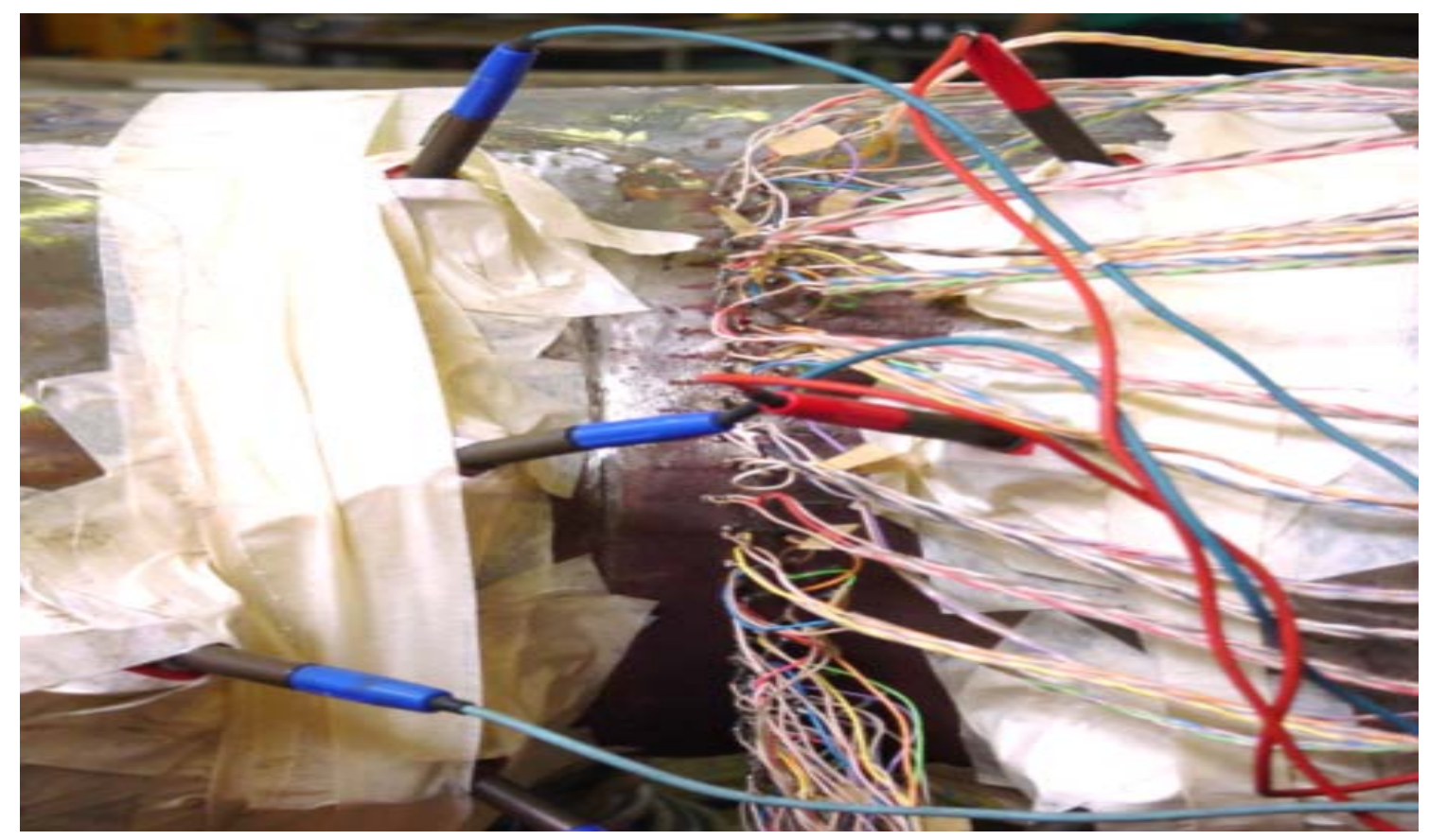

(b) Close-up View of Probes and the Connecting Cables of Specimen S2

Figure 6. Views of Probe Location and the Connecting Cables

\section{FATIGUE TEST RESULTS}

The ACPD crack profiles recorded are shown in Figure 7. The surface crack generated in Specimen S1 was initiated at the heel of the through brace near the ACPD probe P0 and propagated asymmetrically towards to saddle. The surface crack generated in Specimen S2 was initiated at the crown of the through brace near the ACPD probe P0 and propagated towards to saddle symmetrically. Figure 8 shows the surface cracks of both specimens at the through brace. In order to check the actual crack shapes, the tested joints were spilt into two parts along the crack surface (Figure 9). It can be seen that from the ACPD reading and the actual crack surface that the peak HSS positions are corresponding to the deepest position of the crack.

The crack growth curves and there growth rates at the deepest positions at which the cracks penetrated the through brace wall according to ACPD reading are plotted in Figures 10 and Figure 11 respectively. Figure 12 shows the plot of the design S-N curve [12] for a thickness of $19.1 \mathrm{~mm}$ for Specimen S1 and 20mm for Specimen S2 together with the fatigue life (the number of load cycles for the formation first through-thickness crack) of these specimens. It is observed that the S-N curve is only marginally conservative when predicting the life of the joint Specimen S1, while for Specimen S2 the S-N curve is not conservative. 


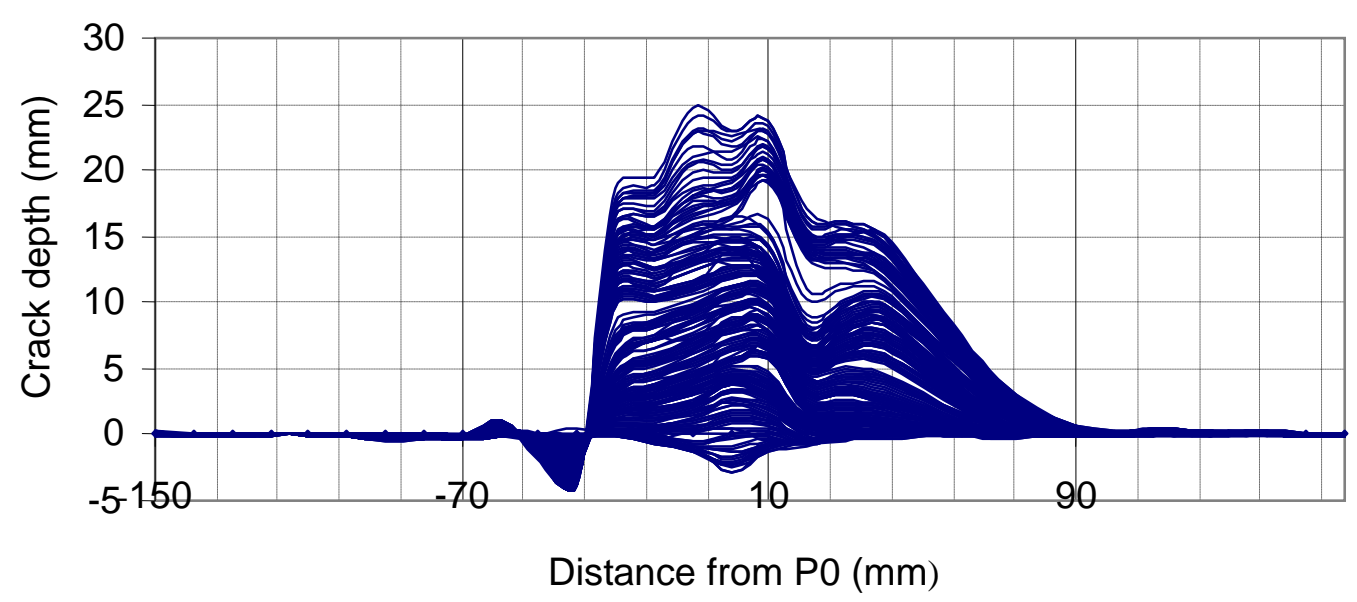

(a) ACPD Crack Development Shape of Specimen S1

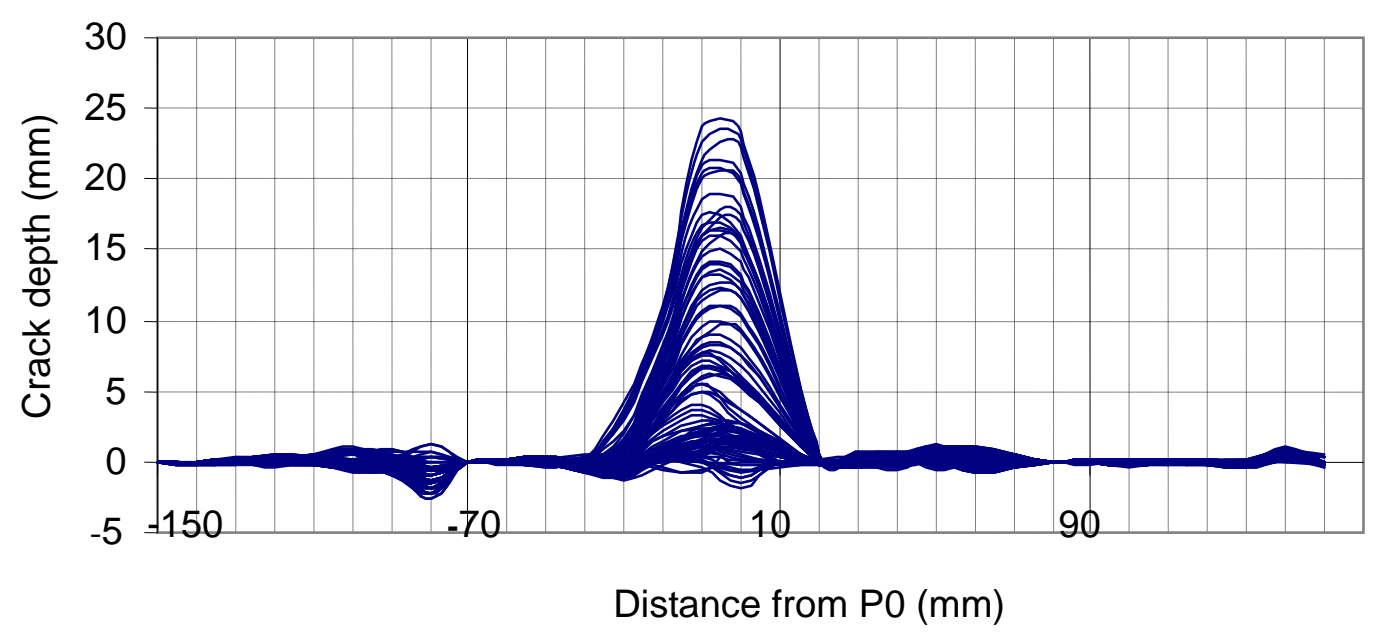

(b) ACPD Crack Development Shape of Specimen S2

Figure 7. ACPD Crack Development of Partially Overlapped CHS K-joints

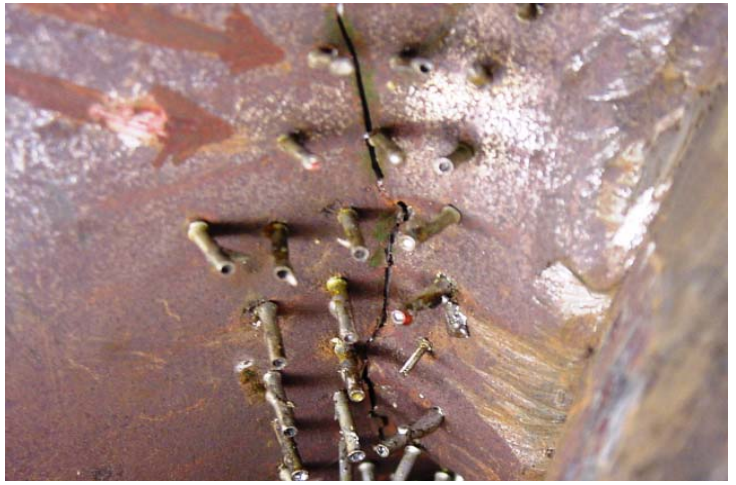

(a) Surface Crack of Specimen S1

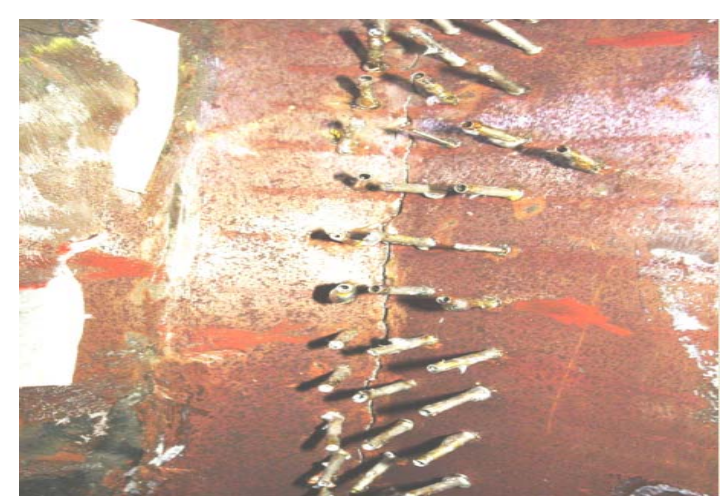

(b) Surface Crack of Specimen S2

Figure 8. Surface Cracks 


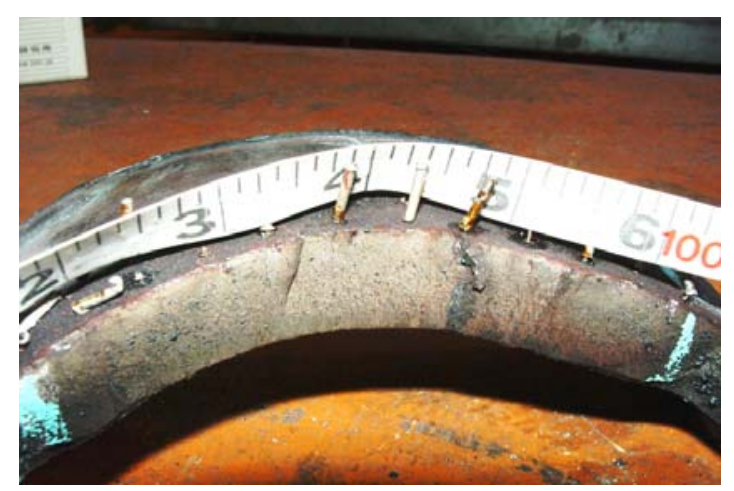

(a) Opened Surface Crack of Specimen S1

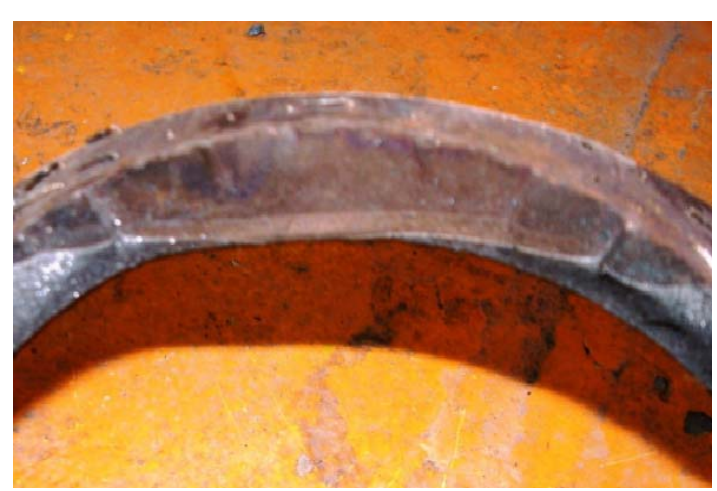

(b) Opened Surface Crack of Specimen S2

Figure 9. Opened Surface Cracks

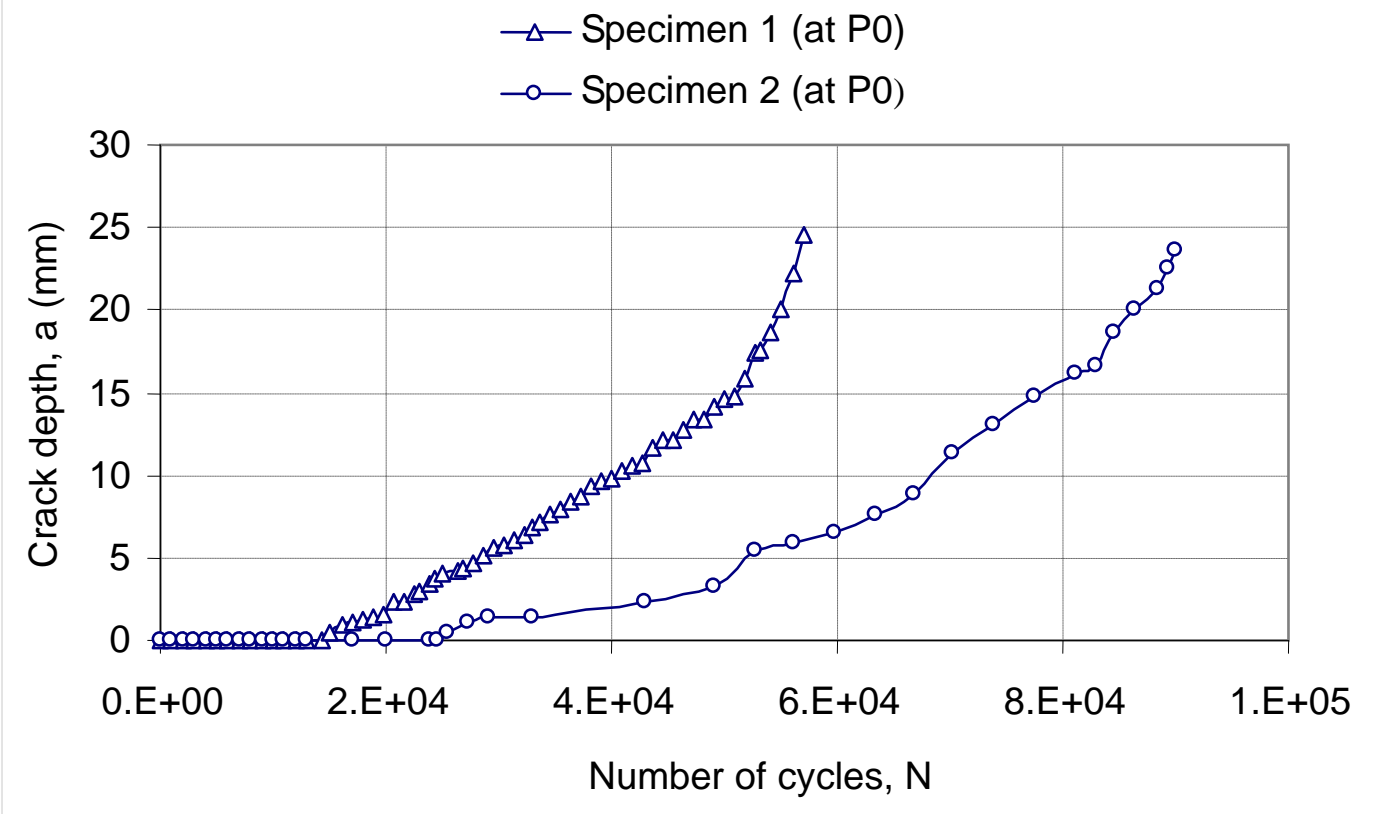

Figure 10. Crack Growth Curves of Partially Overlapped CHS K-joints at the Deepest Position 


$$
\begin{aligned}
& \multimap-\text { Specimen } 1 \text { (at P0) } \\
& \multimap-\text { Specimen } 2 \text { (at P0) }
\end{aligned}
$$

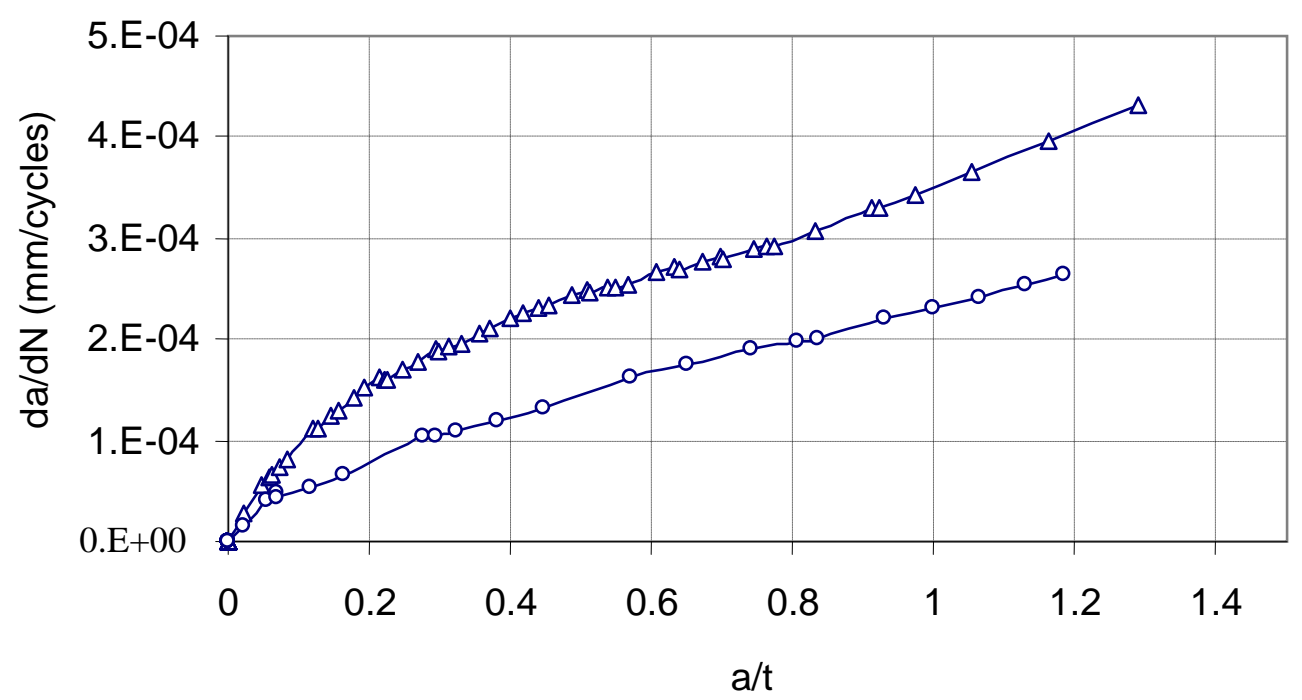

Figure 11. Crack Growth Rates of Partially Overlapped CHS K-joints at the Deepest Position

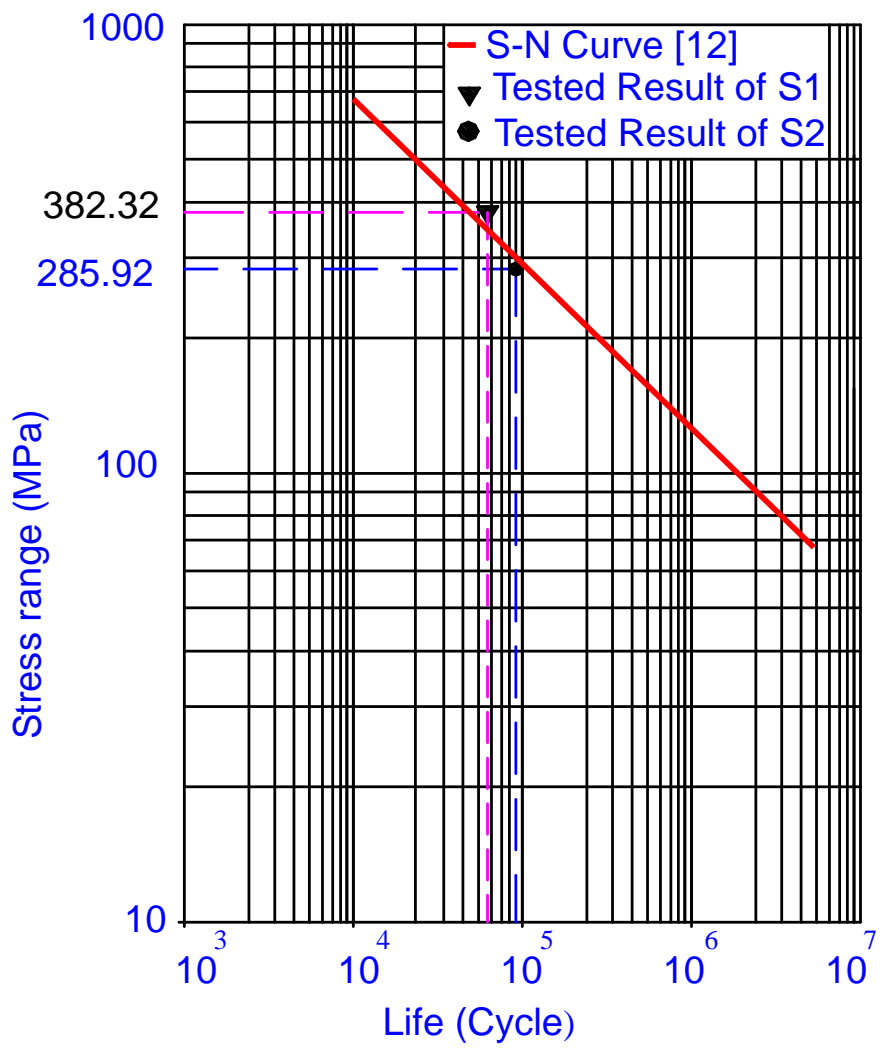

Figure 12. Fatigue Test Results Comparing with S-N Curve Data 


\section{CONCLUSIONS}

1. The stress analysis results show that the HSSs were located on the brace side. This may lead to somewhat shorter fatigue life of this kind of joint compared with previous chord failure mode which is common seen in T-, Y-, N-, and gapped CHS K-joints, since the most of the real offshore structures have a thinner brace thickness than the chord thickness.

2. In addition, the experimental stress analysis also shows that that the Ethymoui's formulae may not be completely suitable for design of partially overlapped CHS K-joints as the results show that the SCF formula values are over-conservative in IPB load case, but in AX load case they are not conservative.

3. Fatigue tests were carried out to investigate the behavior of two partially overlapped CHS K-joints under combined AX and IPB loadings. For Specimen S1, the test results indicated that peak HSS occurred at the through brace weld toe near the heel of the intersection of the through brace and the chord. For Specimen S2, when the IPB loading direction is reversed, the peak HSS occurred at the through brace weld toe near the crown of the through brace and overlapping brace. The fatigue test results demonstrated that the S-N curve proposed in the current codes is marginally conservative when predicting fatigue life of Specimen S1, but for Specimen S2 nonetheless S-N curve is not conservative.

Therefore, the existing formulae and current S-N curves may not be completely suitable for design of partially overlapped CHS K-joints.

\section{REFERENCES}

[1] Tizani, W.M.K., Yusurf, K.O., Davies, G. and Smith, N.J., “A Knowledge Based System to Support Joint Fabrication Decision Making at the Design Stage- Case Study for CHS Trusses", Proceeding of the $7^{\text {th }}$ International Symposium of Tubular Structures, Hungary, 1996, pp. 483-489.

[2] Wardenier, J., “Hollow Section Joints”, Delft University Press, Delft, The Netherlands, 1982.

[3] Romeijn, A., Karamonus, S.A. and Wardenier, J., "Effects of Joint Flexibility on Fatigue Design of Welded Tubular Lattice Structures”, The Seventh International Offshore and Polar Engineering Conference, San Frncisco, USA, 1997, Vol. IV, pp 27-36.

[4] Herion, S. and Puthli, R.S., "Fatigue Design and Secondary Bending Moments in RHS K-joints with Gap”, The Eighth International Symposium on Tubular Structures, Singapore, 1998, pp. 315-322.

[5] Wydle, J.G.. and McDolald, A., "The Influence of Joint Dimensions on Fatigue Strength of Welded Tubular Joints”, Proceeding of $2^{\text {nd }}$ International Conference, Behaviour of Offshore Structures, BHRA Fluid Engineering, Cranfield, U.K. 1979, paper 42, pp. 535-500.

[6] Efthymiou, M. and Durkin, S., "Stress Concentrations in T/Y and Gap/Overlap K-joints", Behavior of Offshore Structures, Elsevier, Amsterdam, Netherlands, 1985, pp. 429-440

[7] Dover, W.D., Dharmavasan, S., Brenan, F.P. and Marsh, K.J., "Fatigue Crack Growth in Offshore Structures”, Engineering Materials Advisory Services (EMAS) Ltd., Chamelon Press, London, 1995.

[8] Chiew, S.P., Lie, S.T., Lee, C.K. and Huang, Z.W., "Fatigue Performance of Cracked Tubular T- Joints under Combined Loads-Part I- Experimental”, Journal of Structural Engineering, American Society of Civil Engineers, ASCE, 2004, Vol. 130, No. 4, pp. 562-571. 
[9] Lee, C.K., Lie, S.T., Chiew, S.P. and Shao, Yongbo, "Numerical Models Verification of Cracked Tubular T, Y and K-Joints Under Combined Loads", Engineering Fracture Mechanics (United States), 2005, Vol. 72, No. 7, pp. 983 - 1009.

[10] Lie, S.T., Lee, C.K., Chiew, S.P. and Shao, Yongbo, "Validation of Surface Crack Stress Intensity Factors of a Tubular K-joint”, International Journal of Pressure Vessels and Piping (United Kingdom), 2005, Vol. 82, No. 8, pp 610 - 617.

[11] Lie, S.T., Lee, C.K., Chiew, S.P. and Shao, Yongbo, "Mesh Modelling of Cracked Uni-planar Tubular K-joints”, Journal of Constructional Steel Research (United Kingdom), 2005, Vol. 61, No. 2, pp 235 - 264.

[12] Zhao, X.L., Herion, S., Packer, J.A., Puthli, R., Sedlacek, G., Wardenier, J., Weynand, K., van Wingerde, A., and Yeomans, N., "Design Guide for Circular and Rectangular Hollow Section Joints under Fatigue Loading”, CIDECT Publication No. 8, TUV-Verlag, Germany, 2001. 